\title{
Body Temperature Measurement: Is the Tympanic Method can be Reliable in Children?
}

\author{
Majid Malaki
}

\section{Majid Malaki \\ Department of Pediatric Nephrology, \\ Sevome Shaban Hospital, Tehran, IRAN. \\ *Correspondence \\ Majid Malaki \\ Assistant Professor of Pediatric Nephrology, Sevome Shaban Hospital, Tehran, IRAN.}

Phone: +989123231477

Email: madjidmalaki@gmail.com

\section{History}

- Submission Date: 17-08-2020:

- Review completed: 20-09-2020;

- Accepted Date: 24-09-2020

DOI : 10.5530/ijcep.2020.7.3.31

Article Available online

http://www.ijcep.org

\section{Copyright}

(C) 2020 Phcog.Net. This is an openaccess article distributed under the terms of the Creative Commons Attribution 4.0 International license.

\section{Dear Sir,}

The central body temperature has been detected in the hypothalamus because it receives its blood from the internal carotid artery; these areas are near to some major arteries like internal carotid, pulmonary artery. Tympanic membrane and esophagus can show central temperature better than other sites (rectum and colon) that are far from carotid. It has been shown that rectal temperature cannot be a reliable site for central temperature detection. ${ }^{[1,2]}$

On contradictory, Shinazaki et al. showed rectal temperature is superior to other methods and can give a reliable result similar to the pulmonary artery and tympanic membrane. ${ }^{[3]}$ Some studies even reported that there is no correlation between rectal, oral and tympanic membrane. ${ }^{[4]}$ It is also true for axillary, tympanic and rectal sites. ${ }^{[5]}$ All these show that the measured temperature is low sensitive in tympanic and axillary method while the rectal temperature is an unusual way for fever measurement. ${ }^{[1,2]}$ There are many contradicting results about best method of temperature measurement. Some studies confirm that a good correlation exists between rectal and tympanic method of temperature detection ${ }^{[6]}$ while other studies claim oppositely and show there is no correlation among rectal, oral and tympanic method. In a cross-sectional study, 50 infants and toddlers with mean age $(28 \pm 10)$ in months (min: 3 , max: 36$)$ were recruited and their temperature was measured. First the temperature was measured by tympanic infrared device method and after one minute, rectal temperature was measured. Data were given as mean $\pm \mathrm{SD}$ and the temperature $\left({ }^{\circ} \mathrm{C}\right)$ between two groups was compared. There was no significant difference $(P<0.1)$ between the temperature measured by tympanic and rectal method in the febrile group subjects whereas statistical difference $(P<0.001)$ was observed between the temperature measured by both the methods in the afebrile group (Figure 1).

Some authors believe that technical error may be a reason for the inaccuracy of the tympanic method for detecting the body temperature which is partly due to the disturbing role of ear channel for heat sensation. ${ }^{[3]}$ The most optimistic difference between tympanic method and rectal method is $0.1^{\circ} \mathrm{C} \cdot{ }^{[7]}$ Other studies claim that the presence of otitis media and cerumen cannot play any destructive role in temperature measurement accuracy by tympanic infrared mechanism devices and the difference

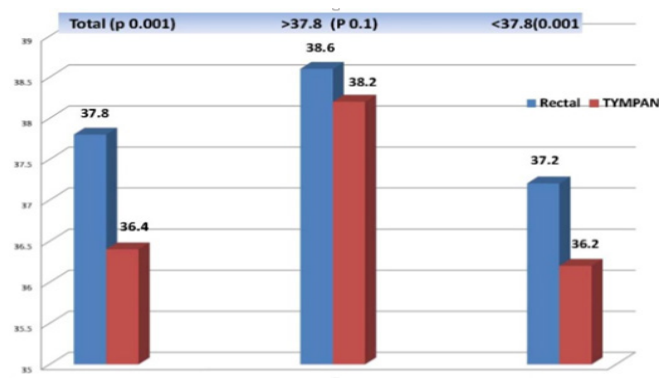

Figure 1: Comparison of rectal and tympanic method shows the rectal gives higher values than tymapanic method. this difference is lowest in febrile group. $\left(0.4^{\circ} \mathrm{C}\right.$ in average)

between tympanic method and rectal method is $0.3^{\circ} \mathrm{C}$ that was not significant. ${ }^{[7]}$ It has been reported that tympanic method is less sensitive in comparison to oral temperature detection and it is confirmed by other studies that show the tympanic method is not reliable in drowning patients. ${ }^{[8]}$ Our study reported that tympanic method is sensitive in detecting temperature in febrile subjects while in non-febrile or hypothermic subjects, as above studies suggested, tympanic method is less sensitive and cannot be a reliable method.

\section{REFERENCES}

1. Benzinger $M$, Benzinger T. Tympanic clinical temperature. In: Herzfeld CM editors. Temperature, its measurement and control in science and industry. New York: Reinhold Publication. 1971;2089-102.

2. Webb G. Comparison of esophageal and tympanic temperature monitoring during cardiopulmonary bypass. Anesth Analg. 1973;52(5):729-33.

3. Shinozaki T, Deane R, Perkins FM. Infrared tympanic ther mometer: Evaluation of a new clinical thermometer. Crit Care Mad. 1988;16(2):148-50.

4. Kenney RD, Fortenberry J. Evaluation of an infrared tympanic membrane thermometer in pediatric patients. Pediatrics. 1990;85(5):854-8.

5. Muma BK, Treloar DJ, Wurmlinger K. Comparison of rectal, axillary and tympanic membrane temperatures in infants and young children. Ann Emerg Mad. $1991 ; 20(1): 41-4$.

6. Ward L, Kaplan RM, Paris PM. A comparison of tympanic and rectal temperatures in the emergency department. Ann Emerg Med. 1988;17:435.

7. Stewart JV. Webster D. Re-evaluation of the tympanic thermometer in the emergency department. Ann Emerg Med. 1992;21(2):158-61.

8. Claus-Martin M, Shank E, Hauser B, Radermacher P. Infrared ear thermometry in water related accidents not a good choice. J Emerg Med. 2010;38(4):417-21.

Cite this article: Malaki M. Body Temperature Measurement: Is the Tympanic Method can be Reliable in Children?. Int J Clin Exp Physiol. 2020;7(3):126. 